\title{
Technology planning approach for Very Small Entities
}

\author{
Aleksander Buczacki \\ Warsaw University of Technology \\ Institute for Production Systems Engineering \\ 86 Narbutta St. room ST120 \\ 02-524 Warsaw, Poland \\ a.buczacki@wp.pl
}

\author{
Claude Y. Laporte \\ École de technologie supérieure \\ Department of Software and IT Engineering \\ 1100 Notre-Dame Street West, Montréal \\ Québec H3C 1K3, Canada, \\ Claude.Y.Laporte@etsmtl.ca
}

Copyright $\odot 2016$ by A. Buczacki, C.Y. Laporte. Published and used by INCOSE with permission.

\begin{abstract}
Systems engineering is usually seen as the domain of large enterprises. However, small and medium sized (SMEs) and micro-enterprises are coming to play an ever-larger role even in industries traditionally dominated by large enterprises. In new product development projects carried out by SMEs or micro-enterprise using systems engineering, three aspects should be noted. Firstly, such enterprise wants to initiate the project independently, i.e. develop a new product/system under ISO 29110 , there is some information regarding how it could do it, i.e. the stage that would involve the definition of the requirements. But enterprise should be able to understand and apply this information. Secondly, it must be underlined that project execution, is preceded by establishment of cooperation of new product development process. This process is frequently tedious, time-consuming and especially for small organizations - troublesome. Thirdly, such cooperation should be anchored in the strategy especially in technology strategy of the company. Technology roadmapping could be considered as a tool which is helpful in technology strategy creation process.
\end{abstract}

\section{Introduction}

Systems engineering is usually seen as the domain of large organizations that possess a high technology potential and employ many engineers. However, due to globalization processes, small and micro-enterprises (fewer than 9 employees) are coming to play an ever-larger role even in industries traditionally dominated by large enterprises. The importance of micro-, small and medium-sized enterprises in the European economy is very high - they form its core. Data on the numbers of enterprises in each category is presented in table 1.

Table 1. European Structural Business Statistics for 2011 (Source: Eurostat, after Moll 2013)

\begin{tabular}{|l|c|c|c|c|}
\hline Type of enterprise & $\begin{array}{c}\text { No. of } \\
\text { employees }\end{array}$ & $\begin{array}{c}\text { Annual } \\
\text { turnover (EUR) }\end{array}$ & $\begin{array}{c}\text { No. of enterprises } \\
\text { (\% of overall) }\end{array}$ & $\begin{array}{c}\text { No. of } \\
\text { enterprises }\end{array}$ \\
\hline \hline Micro-enterprises & $1-9$ & $\leq 2$ million & 92,2 & 19968000 \\
\hline Small enterprises & $10-49$ & $\leq 10$ million & 6,5 & 1358000 \\
\hline Medium enterprises & $50-249$ & $\leq 50$ million & 1,1 & 228000 \\
\hline SMEs total & 87100000 & & 99,8 & $21544000^{1}$ \\
\hline Large enterprises & $>250$ & $>50$ million & & \\
\hline Large enterprises total & 42900000 & & 0,2 & 43000 \\
\hline
\end{tabular}

\footnotetext{
${ }^{1}$ Independent companies only, excluding legally independent companies that are part of large enterprises.
} 
Most enterprises operating in the EU fall into the categories of micro-, small and medium. Additionally, it can be stated based on the example of Poland, as illustrated in table 2, that micro-enterprises are the main category whose numbers are increasing, while the number of enterprises in the other categories keeps declining (comparing 2011 and 2012). The decline in the proportion of large and very large enterprises is a cause for concern.

Table 2. Structural Business Statistics for 2010-2013 in Poland (Source: Central Statistical Office in Poland)

\begin{tabular}{|c|c|c|c|c|c|c|c|c|c|}
\hline $\begin{array}{l}\text { Type of } \\
\text { enterprise }\end{array}$ & $\begin{array}{c}\text { No. of } \\
\text { employees }\end{array}$ & \multicolumn{2}{|c|}{2010} & \multicolumn{2}{|c|}{2011} & \multicolumn{2}{|c|}{2012} & \multicolumn{2}{|c|}{2013} \\
\hline "Micro & 189 & 373713677 & $94,98 \%$ & 3674970 & $94,96 \%$ & 3794489 & $\overline{995,45 \%}$ & 3890686 & $\overline{95,59 \%}$ \\
\hline Small & $10-49$ & 161550 & $4,13 \%$ & 160851 & $4,16 \%$ & 146489 & $3,68 \%$ & 145425 & $3,57 \%$ \\
\hline Medium & $50-249$ & 29731 & $0,76 \%$ & 29340 & $0,76 \%$ & 29787 & $0,75 \%$ & 29637 & $0,73 \%$ \\
\hline Large & $250-999$ & 4033 & $0,11 \%$ & 3922 & $0,10 \%$ & 3779 & $0,10 \%$ & 3736 & $0,09 \%$ \\
\hline Large & $>999$ & 811 & $0,02 \%$ & 814 & $0,02 \%$ & 790 & $0,02 \%$ & 775 & $0,02 \%$ \\
\hline & Total & 3909802 & $100,00 \%$ & 3869897 & $100,00 \%$ & 3975334 & $100,00 \%$ & 4070259 & $100,00 \%$ \\
\hline
\end{tabular}

It should be noted that the competitiveness of Polish small and medium enterprises (SMEs) operating in the industries where process engineering can be applied is relatively high. The active use of IT and remote communication makes it much easier for them to operate on global markets than in the past. They usually operate as sub-contractors for large enterprises, carrying out specific tasks/ projects with predefined requirements. A high number of small and micro-enterprises are active in IT in Poland. Other sectors for which this is true include: aerospace, automotive, health (excluding healthcare facilities). As subcontractors, SMEs begin their work on a project after the requirements have been defined. For this reason, the ISO/IEC 29110 standards and technical reports (ISO 2014) can be very helpful to them. (So far, no enterprises in Poland are using ISO 29110. Work on a standard on the use of systems engineering (SE) for very small entities (VSEs) (i.e. enterprises, organizations, projects having up to 25 people) began in November 2011 within the ISO Working Group24 (Laporte, Houde, Marvin 2014). The ISO 29110 standard and guides are applicable to VSEs involved in the development of non-critical systems. ISO 29110 defines a four-step roadmap also called profiles (ISO 2014):

- Entry - targets VSEs typically developing 6 person-month Project or start-ups;

- Basic - targets VSEs developing only one project at a time;

- Intermediate - targets VSEs developing multiple projects with more than one team;

- Advanced - targets VSEs which want to sustain and grow as an independent competitive software / system development business.

So far, the SE Entry (ISO 2015) and Basic (ISO 2014) profiles have been published by ISO. The development of the Intermediate profile has started in February 2016. We expect the management and engineering guide of the Intermediate profile to be published in late 2017 or early 2018.

The results of the work by the ISO WG 24, are international standards and technical reports, such as management and engineering guides, dedicated to VSEs The guides are supplemented with Deployment Packages (DP's), the use of which may be recommended but is not required. Users can use the DP's as they see fit. It is assumed that each stage of the roadmap, or profile, can have a dedicated set of Deployment Packages. The list of Deployment Packages dedicated to the SE Basic Profile are (ISO 2014):

- Change Management;

- Configuration Management; 
- Functional \& Physical Architecture;

- Interface Management;

- Integration;

- Product Deployment;

- Project Management;

- Requirements Engineering;

- Verification \& Validation.

The utilization of ISO 29110 allows VSEs to gain quantifiable benefits (Laporte, Chevalier 2015 and Laporte, Hébert, Mineau 2014). Analysis of the Guide and selected DP's shows that it assumes the ISO 29110 users already possess defined requirements - statement of work is available. Based on this definition, the work performance method is planned and subsequently carried out. DPs support the plan, maintaining systems engineering standards in line with the so-called SE technical processes (Walden and all 2015):

- Business or mission analysis process;

- Stakeholder needs \& requirement definition process;

- System requirements definition process;

- Architecture definition process;

- System analysis process;

- Implementation process;

- Integration process;

- Verification process;

- Transition process;

- Validation process;

- Operation process;

- Maintenance process;

- Disposal process.

In new SE product development projects, carried out by VSEs, three aspects should be noted:

- If a VSE wants to initiate the project independently, i.e. develop a new product/system using ISO 29110, there is some information regarding how it could do it, i.e. the stage that would involve the definition of the requirements. But VSEs may not be able to understand and apply this information. The standard assumes that the enterprise already possesses the defined requirements.

- It must be underlined that project execution, is preceded by establishment of cooperation in the field of research and development both technology and product. This process is frequently tedious, time-consuming and - especially for small organizations - troublesome. In fact, it can be so drawn-out that it lasts longer than the cooperation itself. That is why the establishment of cooperation for a small organization may be very important.

- Small organizations very often are not operating in strategic way. Even relating to technology development they usually do not take into consideration long periods. So, a small company should operate in more strategic way, if would like to obtain a much value as possible from the research and development cooperation with external organizations.

\section{Definition of new product opportunities through VSEs}

As mentioned above, the published ISO 29110 focuses mainly on the new product / system design process from the moment of system requirement definition to validation of the developed system. ISO 29110 systems engineering management and engineering guides lacks indications on how the system requirements should be formulated. These indications should first of all aid VSEs in identifying 
current and future stakeholders and performing ongoing analysis of their requirements, including the means of data acquisition, their interpretation, prioritization and determination of the significance of individual data items. In addition they should cover the following issues relevant to work performance:

- How to identify product opportunities. It is recommended that the following criteria be taken into consideration for new product opportunities (adapted from Christensen 1997):

- Market size (units/year x average price);

- $\quad$ Market growth rate (percent per year);

- Competitive intensity (number of competitors and their strengths);

- Depth of the VSE's existing knowledge of the market;

- Depth of the VSE's existing knowledge of technology;

- Fit with the VSE's other products;

- $\quad$ Fit with the VSE's capabilities;

- $\quad$ Potential for patents, trade secrets, or other barriers to competition;

- Existence of a product champion within the VSE;

- Means of analyzing technological progress.

The above dataset should enable the formulation of the requirements for the future product/system. If the VSE is a subcontractor or a vendor, the analysis should also cover the potential / strategy of the principal organizations (VSE's contractors).

The methods of technical knowledge acquisition differ between enterprises and industry domains. Those used most commonly are (Lichtethaler 2004):

- Customer or market survey;

- Internal analysis (e.g. brainstorming);

- External analysis (e.g. benchmarking, Delphi analysis or expert opinion);

- Scenario development;

- Product technology roadmapping;

- Experience curves.

It should be noted that not all of these are available to small organizations and VSEs and that their usefulness may differ depending on industry. Presented in table 3 are the results of research on the usefulness of individual market analysis techniques in the context of acquiring information on new directions of activity and information needed to defined future product requirements.

Table 3. Use and Usefulness of Techniques for Product and Service Development (Tidd, Bodley 2002)

\begin{tabular}{|l|c|c|c|c|}
\hline \multirow{2}{*}{ Forecasting metod } & \multicolumn{2}{|c|}{ High-novelty / Radical Project } & \multicolumn{2}{c|}{ Low-novelty / Incremental projects } \\
\cline { 2 - 5 } & Usage [\%] & Usefulness & Usage [\%] & Usefulness \\
\hline \hline Segmentation & 89 & 3,42 & 42 & 4,50 \\
\hline Delphi / Industry Experts & 63 & 3,83 & 37 & 3,71 \\
\hline Surveys / Focus groups & 52 & 4,50 & 37 & 4,00 \\
\hline User-practice observation & 47 & 3,67 & 42 & 3,50 \\
\hline Scenario development & 21 & 3,75 & 26 & 2,80 \\
\hline
\end{tabular}

In practice it could very difficult to perform all staff mentioned above by single organization. Small organizations very frequently use materials, such as technology roadmaps for the different industries, regional innovation strategies, prepared by external organizations, so-called organizations of the surroundings of business. Such materials are unfortunately typically characterized by a rather high level of generalization since they must be suitable for a large number of users. For that reason, the usefulness of such materials is frequently doubted by potential customers and they are used mainly to obtain initial knowledge on the subject. 
The search for new product opportunities is frequently conducted through formal and informal networks available to the VSEs (in practice, VSE's leaders, Top-managers). In addition, the new product portfolio depends to a large extent on the organization's operating strategy, even when such a strategy is not formally defined.

\section{Creating VSE technology strategy}

The planning-based strategy development approach has been criticized by representatives of both business and science. Under the planning approach to strategy development it is assumed that the current situation will persist in the future or that it will be in line with assumptions (Mintzberg 1994). It is also assumed that it is possible to predict future market conditions and conditions within the enterprise. Unfortunately, in the case of seeking new market and product opportunities, the commonly used forecasting methods such as trend extrapolation and time series analysis are not very useful due to the lack of historical information (Tidd, Bessant 2009). Another important thing, such approach is completely useless for VSEs.

In addition, when formulating plans, the main emphasis is put on procedures rather than the actual content of the plans. What's more, the business environment changes so rapidly that it is difficult to develop a detailed operating plan, and therefore in practice, VSEs use an approach going from the general to the specific in drawing up their plans, taking several alternative solutions (scenarios) into account. This can be achieved through technology roadmapping, a tool that integrates future products with the current and future potential of a VSE.

Presently, the results of work in one area (i.e. on one product) are more frequently used in the development of other products / other industries. For this reason, the technology development and implementation process should always be considered in the context of its eventual application /-s.

When developing strategy for a specific organization - enterprise - we focus more on outlays than the effects the undertaking's completion will have on the organization. In this situation, planning is related to strategic planning or operational planning. The technology strategy development process could consist of the following steps (Buczacki 2015):

1. Analysis of the organization's surroundings, including current and target market analysis, analysis of technologies and the level of development and availability. In parallel, an internal analysis of the organization including its strategy, processes, resources and competences.

2. Definition of target markets and products available on them.

3. Definition of technologies used in current and future products and to produce current and future products.

4. Definition of level of technology development (e.g. Technology Readiness Level, TRL) and the technology's impact on the organization's competitive position (e.g. is it a base, key, advancing or emerging technology).

5. Definition of the technology development plan.

6. Implementation of the technology development plan, including any necessary modifications.

Technology development strategy is the outcome of overall business strategy which defines, among others, what products will be offered on what markets. Technology strategy is usually closely correlated with product development strategy and frequently also with product innovation implementation strategy. Enterprises usually develop technologies with the following objectives in mind (Roussel, Saad, Erickson 1991):

- To support current areas of activity (businesses, product groups etc.),

- To support areas of activity,

- To develop in-house technology potential. 
The achievement of each of these objectives requires a different management approach, different effectiveness indicators etc. Also, frequently different departments / functions - marketing, production or technology - are interested in pursuing different objectives.

Decisions taken by entrepreneurs depend on the specific part of the product lifecycle which consists of the following phases (Based on Grudzewski, Hejduk 2008):

- Introduction of product on the market - preceded by research (basic and applied). The enterprise focuses on building awareness of the product's existence among potential customers, creating a desire to try/purchase it. At this stage, it usually does not yet obtain a return of its investment into developing and implementing the new product.

- Increased sales - the enterprise undertakes actions aimed at maintaining rapid sales growth for the longest time possible. The enterprise usually obtains a return of the funds invested in the product development and implementation at the end of this phase.

- Maturity - characterized by a fall in the rate of sales. This is also the longest phase. During it, enterprises frequently introduce new products on the market.

- Decline in sales - is caused by the appearance of successive innovations, changes in the customers' tastes or increased competition. As a result, the industry experiences an excess of production capacities and a decrease of profit. The best option for an enterprise with a product in the decline phase is to have another in the increased sales phase.

New product introduction depends on the type of product innovations that can be classified as follows based on originality, geographical extent, impact on consumers' behavior or the means of the enterprise's acquisition of novel elements:

- New to the world - new products creating an entirely new market;

- New product lines - new products allowing a company to enter an already existing market;

- Additional products - new products supplementing current lines;

- Improvements of current products - new products with improved performance or higher perceived value, introduced on the market to replace existing products;

- Repositioned products - existing products targeting new markets or market segments;

- Products reducing costs - new products fulfilling similar functions at a lower cost.

Technologies exhibit a characteristic similar to the product lifecycle. There exist mature technologies which are used widely in traditional industry.

Each product innovation also requires the application of various technologies (i.e. process innovations), including technologies in various phases of their lifecycles; as with the product lifecycle, these are the development, growth, maturity and decline phases. Table 4 presents the types of technology used by enterprises with respect to their competitive potential.

Table 4. Technology types (Based on Floyd 1997)

\begin{tabular}{|l|l|l|}
\hline Technology type & \multicolumn{1}{|c|}{ Description } & \multicolumn{1}{|c|}{ Strategic decisions } \\
\hline \hline Base & $\begin{array}{l}\text { Essential to be in the business, widely exploited by } \\
\text { competitors, little competitive impact. }\end{array}$ & Selective withdrawal \\
\hline Key & $\begin{array}{l}\text { Well embodied in products and processes, high } \\
\text { competitive impact. Usually very closely guarded. }\end{array}$ & $\begin{array}{l}\text { Development and } \\
\text { systemic control }\end{array}$ \\
\hline Pacing & $\begin{array}{l}\text { Under experimentation by some competitors, } \\
\text { competitive impact likely to be high. }\end{array}$ & Selective investment \\
\hline Emerging & $\begin{array}{l}\text { At early stage of lifecycle (applied research or } \\
\text { early development work). Competitive impact } \\
\text { unknown, but promising. }\end{array}$ & Monitor \\
\hline
\end{tabular}

Technologies should be classified in relation to specific industries/products or enterprises since in 
different industries, a given technology may be seen as either base or key.

Frequently, the technology lifecycle does not match the lifecycles of the products offered by the enterprise, e.g. in the case of laundry detergents which as a product are in the mature phase of their lifecycle but are produced using modern chemicals which are in the emerging phase. Technology roadmapping is helpful in defining technology strategy and in subsequent steps, also future product opportunities.

\section{Technology roadmapping as a tool for determining new product opportunities}

Currently, most technologies are developed through multi-year interdisciplinary scientific / research / development programs. The process of preparing and carrying out such programs is characterized by a high level of complexity. This has led to the need to develop tools to assist the management of the development and implementation of such programs. These tools are characterized by the following properties:

- They comprehensively cover all the issues related to the development of new technology, implementation and launch of products or processes that use this technology, establishing the so-called road map. This property serves to integrate various (i) groups (e.g. scientists - idea and research; engineering staff - development work and production; marketing - market studies and sales), (ii) ways of working, and (iii) management styles.

- They facilitate communication between the teams involved in the implementation of the project, highlighting the role and contribution of the results of the teams to the success of the entire project.

- They enable more effective management of scientific research resources (personnel, equipment, capital).

One of the tools used in research program planning, organization and performance is technology roadmapping, aimed at developing a roadmap showing the way toward the market implementation of a technical solution (Phaal, Farrukh, Probert 2004, EIRMA 1997).

This tool is used primarily in large industrial enterprises whose activity is based on modern technology. This tool was first used ca 30 years ago by Motorola to support product and technology development processes. Specifically, technology roadmapping is used in strategic technology development planning in large enterprises. The roadmap format is that used most frequently by industrial enterprises. An important aspect of each roadmap is the planning horizon. In the case of industrial enterprises, it is usually 10 years. In planning development programs for whole industries or scientific disciplines, on the other hand, the horizon is much longer. In industries with short lifecycles, such as IT, the horizon is much shorter.

It should be mentioned that the tool supports the product and service planning and development process, taking into account all the phases of the innovation process from the moment of idea development through basic research, applied research, production implementation, to market introduction of a new product. Specifically, the tool helps in coordinating the assembly of the elements (technologies, intermediate products) required for the market introduction of the finished product. The developed roadmap assists the team responsible for developing a new product and introducing it in the market (these are usually vary large interdisciplinary teams involving people from different organizational units - the research, technical, production and sales departments - and external experts) understand the level of progress of the work on the development and market introduction of the product.

From the point of an enterprise that uses technology roadmapping, another very important element of product development planning is the ability to plan the resources required to develop a new product and 
introduce it on the market. This is true both of technologies which the enterprise has in hand (including maintenance of technical and quality parameters) and appropriate possibilities / production potential and resources related to promotion, distribution and sales necessary for the product's market implementation. It should be remembered that at each stage of the innovation process, enterprises operating on commercial principles balance current and future expenditures with the expected revenues / benefits which in the case of new solutions will frequently in the distant future. A roadmap usually consists of several layers (Based on: Phaal, Farrukh, Probert 2004):

1. Markets - current and target

The objective of the analysis of this layer is to:

- Define market current and future development determinants, including the most important trends and priority development directions;

- Define business/enterprise/organization/project team development determinants;

- Identify gaps between current and target market.

The analysis within this layer covers the various areas of the market on which the future product will be offered. The market analysis at this point should be as broad as possible. The analysis should not just cover the customer-users of the system but also all the organizations involved in the creation, utilization and recycling of the new product. Of particular use at this stage are the following strategic analysis tools:

- PEST analysis, which focuses on the enterprise's further surroundings, considered in the following aspects P (Political), E (Economic), S (Social), and T (Technological).

- Porter's 5 forces analysis, focusing on the enterprise's immediate surroundings and assumes that competitiveness in each industry is determined primarily by the following factors/forces: (I) rivalry among existing competitors, (II) bargaining power of suppliers, (III) bargaining power of customers, (IV) barriers to new entrants, (V) threat of substitution.

An internal strategic analysis of the enterprise is also conducted at this layer - usually in the form of a SWOT analysis which focuses on the definition of the enterprise's (I) strengths, (II) weaknesses, (III) opportunities that may appear in the future, (IV) threats that mat appear in the future.

After making a "snapshot" of the current conditions of the surroundings and the enterprise's potential, the change directions in the context of the Technology Map formulation are defined.

2. Products

The objective of the analysis of this layer is to:

- Define future product generations;

- Define the impact of market changes in the future and their influence over new product generations;

- Define product development strategy;

- Identify gaps between current and target products.

Within this layer, a very specific analysis of the needs and expectations of the potential customers identified during the market analysis is performed. Also at this stage, the assumptions are made regarding the performance parameters of the future products. The performance parameters help guide the work on the technical parameters of a given product and, in a very general way, the technologies used in the product itself and in the process of its manufacture.

Another important element within this layer is analysis on the production capacity of the 
product being designed. This issue is very important for every enterprise, since the costs of implementing a product's manufacture are usually much higher than those of developing a new product.

\section{Technologies}

The objective of this layer is to:

- Define future technology needs;

- Define the impact of current product generations on new products and indicate the necessary technologies;

- Define a technology development strategy, specifying which technologies will be developed independently and which will be developed within partnerships or outsourced;

- Identify gaps between current technology solutions and those that will be required in the future.

The analysis at this layer includes defining the scopes of the research projects necessary for the development and market implementation of a new product.

\section{4. $\mathrm{R} \& \mathrm{D}$ projects}

An important stage of technology map development is the analysis of the impact of the individual layers on the final result of the undertaking and definition of the interrelations between the individual layers. In practice, this stage usually concludes the technology map development process (Figure 1).

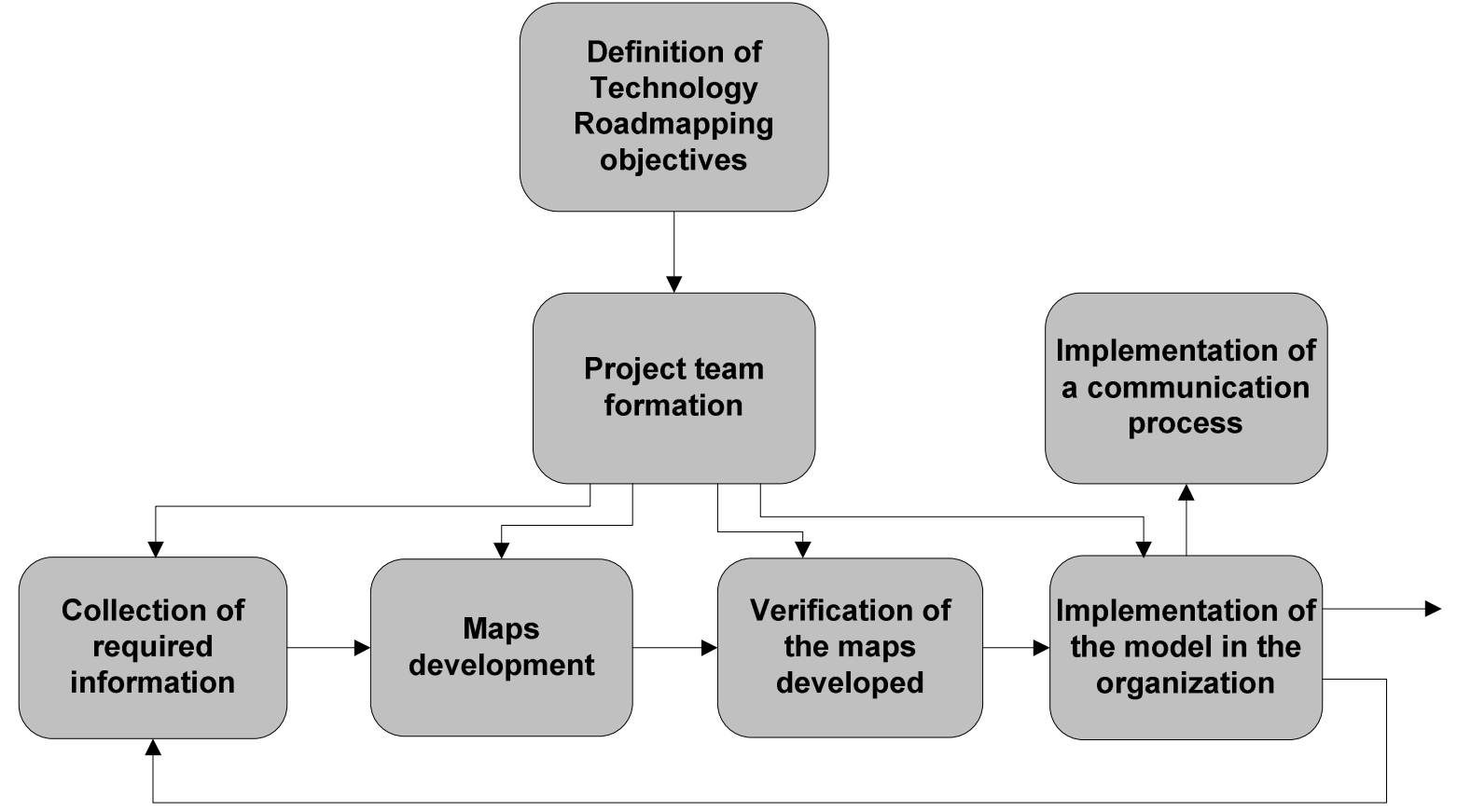

Figure 1. The Technology Roadmapping process (Buczacki 2015)

The technology road mapping process could consist of the following 6 stages:

1. Definition of the objectives of the technology roadmapping in the context of the requirements of the organization/project.

2. Formation of the project team and definition of its work program.

3. Collection of required information, including:

3.1. definition of the priority factors creating added value for the user, taking into account 
current and future user needs,

3.2. mapping key characteristic values on the time axis,

3.3. evaluation of the technology's availability,

3.4. definition of resource requirements.

4. Verification of the maps developed, involving external persons and taking into account the interests of all the stakeholders, including:

4.1. evaluation of interdependencies,

4.2. evaluation of alternative solutions/scenarios,

4.3. evaluation of own (organization, enterprise) strengths and competitive position.

5. Implementation of the model in the organization and adaptation of their method to the organization's particular needs to ensure, among others, technology roadmapping result repeatability, including:

5.1. integration of the technology roadmapping process with the organization,

5.2. assigning people, processes, resources to the actions initiated based on the maps,

5.3. allocation of product life cycles to developed maps,

5.4. confirming assumptions and business impacts,

5.5. taking into consideration the organization's/undertaking's entire product and service portfolio;

5.6. taking into account the proposed and agreed improvements to the maps.

6. Implementation of a communication process, including:

6.1. development of communication standards / patterns,

6.2. documentation of technology roadmapping results,

6.3. formulation of communication policy/strategy/mechanisms.

The principal result of technology roadmapping are the maps that provide support to the enterprise's or undertaking's top management in strategic product or technology development decision making.

Experience shows that the best results can be attained by using a workshop approach (EIRMA 1997). The maps are developed over the course of several workshop sessions, with participants including not just people involved with the enterprise/undertaking but also external persons who provide expert knowledge in areas which are not directly related but which may impact the object of the technology roadmapping. The workshops are supplemented with the results of surveys and questionnaires.

The benefits of implementing technology roadmapping are:

- Better correlation of business objectives with the product and technology objectives of the undertaking,

- More effective management of the undertaking's/enterprise's/organization's research, technology and production,

- Easier evaluation of the impact of the strategic decisions made on the project's future,

- Greater transparency of the strategic decision making,

- Focus on proactive planning (creating the future) instead of reactive planning (responding to the changes occurring in the closer and more distant surroundings).

Application of the technology road mapping approach to the development of batteries for electric vehicles 
The aim of the project, which uses technology roadmapping approach, was to develop a device for use in batteries for electric vehicles.

Electrochemical battery as a power source (characterized by a very high energy density) is today one of the most critically assessed electromechanical components of electric vehicle. The reasons for such assessment are the lack of satisfaction about the distance that an electric vehicle can operate without recharging the battery and the cost of such batteries. In order to eliminate these obstacles, intensive work aimed at reducing the cost of manufacture of the battery was undertaken. In addition to this research, led mostly by large companies or consortia formed by large companies, work to extend the lifecycle of batteries was also carried out, through the use of more efficient battery management systems (BMS).

The initiator of this project of a SE approach was a small Polish company, which is the coordinator of the project consortium, aiming to develop and implement a new product - a BMS module targeted to electric vehicles. Fit was the first time, despite the relatively long time of operating on the market, that a project of such large scope and complexity (research and development activities) has been executed. The consortium consists of several entities: they are companies and research institutions including academia. Most of the research and development work was carried out from their own funds, complemented with some public funds.

Implementation of research and development was planned for a period of 18 months. The project involved 15 persons (e.g. research and technical staff). Figure 2 presents a scheme of the project technology roadmap which shows the most important stages of the project.

The roadmap presents relations between project tasks, relations between particular subsystems (elements) of "final product" as well as stages of project realization also taking into account time perspective. Each element (box) of the roadmap was decomposed and described (it was a separate deliverable of the project). Each task had the owner, some tasks performed by a few consortium partners. The roadmap consists of several layers (market, product, technology, project resources). At the product layer indicated some prototypes, test benches, at the technology layer indicated mostly workpackages, at the project layer - tasks.

The technology road mapping approach has been initiated during the planning stage of the Project. Initially, the road mapping team consisted from two sub-teams: a permanent team and a variable team. The permanent team consisted of representatives of participating companies acting as coordinators of the project, technical managers and external consultants responsible for the technology road mapping. A composition of the variable team, depended on the scope of the performed tasks. It consisted of representatives of the institutions participating in the project, including those responsible for specific tasks.

The technology roadmap was changed several times under complection of the project. The permanent roadmapping team was responsible for roadmap update and whole roadmapping team was responsible for the integration activities and interface management. 


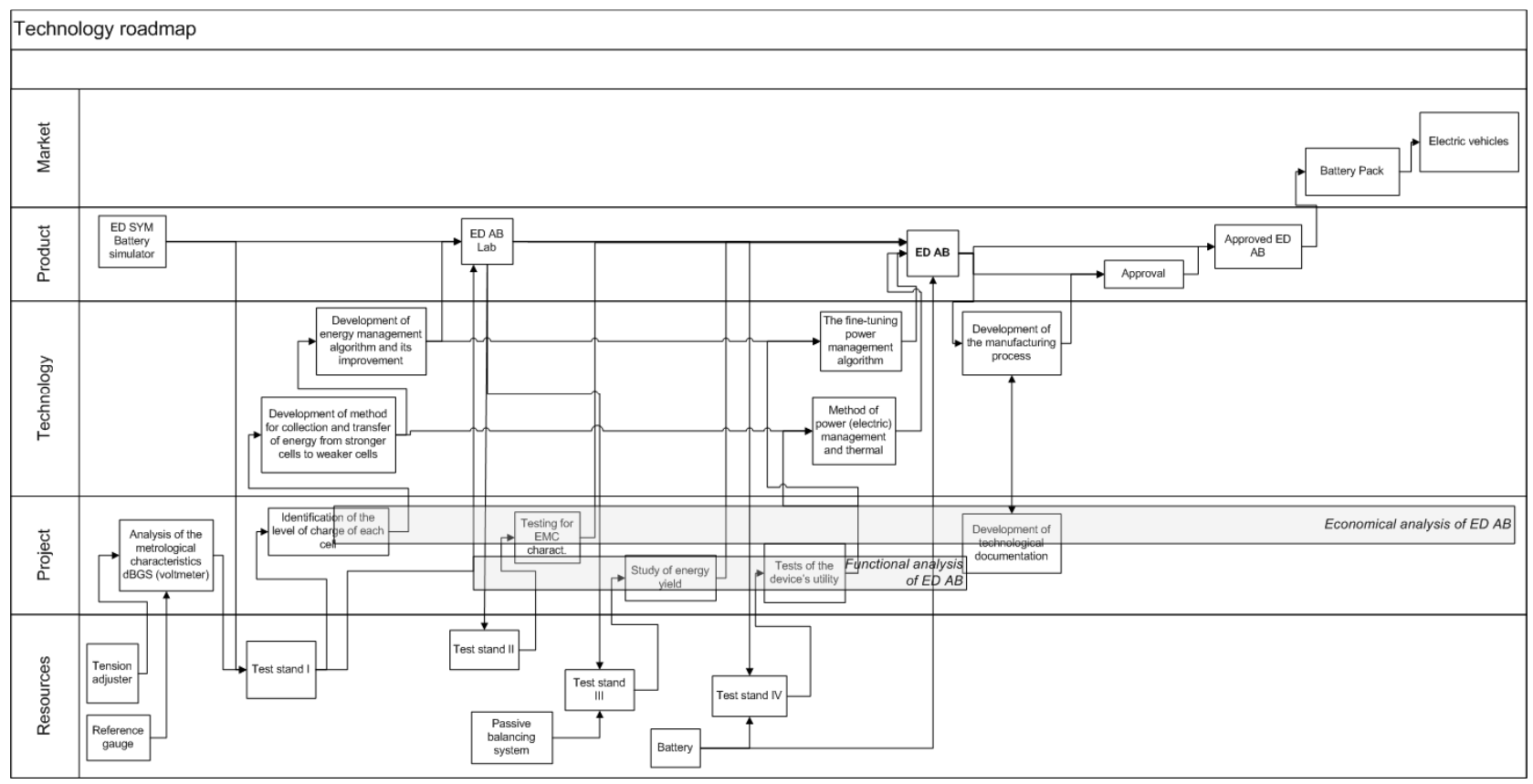

Figure 2. Example of Technology Roadmap (Based: Buczacki 2015)

\section{Conclusion}

Most of the tools described above were developed to be used by large organizations. For this reason, further work is required to adapt them to the needs of small organizations and VSEs. This concerns primarily technology roadmapping and to a smaller extent, technology strategy development.

Another issue that needs to be resolved is to what profile these tools should be targeted and whether they require additional Deployment Packages or they can be included in existing Deployment Packages. At first glance, they are unnecessary for the ISO 29110 Entry (ISO 2015) and Basic (ISO 2014) profiles. In organizations that carry out several projects simultaneously or initiate projects by themselves, tool and methodological support may be desired. For that reason, it is recommended that in the ISO 29110 Intermediate and Advanced profiles, the issue of seeking new product and service opportunities and product and service portfolio strategic management be considered.

An important factor in the technology strategy development process is the ability to work within networks since small organization's competences are often insufficient to cover the entire value chain within which they operate.

The immediate surroundings have a large influence on the competitiveness of small organizations and especially small enterprises and VSEs. An important role is played by organizations of the business environment such as:

- Regional and national business chambers in individual sectors;

- National and local government enterprise support agencies;

- Industry associations of representatives of business, science and financial institutions (business angels, venture capital funds).

Such organizations can catalyze development processes of VSEs in their area of operation. Their activeness and the level of services they provide frequently determine the competitiveness of the enterprises operating in a given geographical area (region, state, country).

For a consortium that consists of small entities, the technology roadmapping approach could be helpful in coordinating new product development programs in which are involved several partners 
from business and technical point of view. In particular, technology roadmaps show which tasks should be performed by each partners as well as an indication of the timing of tasks. Implementation of a technology roadmapping approach could make possible to obtain following benefits (for each consortium partner and program as a whole):

- Strong linkages between technology resources and business drivers;

- Effective allocation of resources (in particular technology and manufacturing);

- Easier evaluation of strategic decisions (transparency);

- Strong focus on pro-active planning instead of a re-active planning.

\section{References}

Buczacki A. 2015, New product planning and development - strategic aspects (in Polish: Planowanie i rozwój nowych produktów - aspekty strategiczne), pp. 95-114, in Wirkus M., Lis A., Technical and marketing technology development planning (in Polish: Techniczne i marketingowe, planowanie rozwoju technologii), CeDeWu.

Christensen C. 1997, The Innovator's Dilemma: When New Technologies Cause Great Firms to Fail, Boston, Harvard Business School Press.

EIRMA 1997, Working Group report 52 Technology Roadmapping, Paris.

Floyd C. 1997, Managing technology for corporate success, Hampshire, Gower Publishing Limited.

Grudzewski W., Hejduk I. 2008, Technology management. Problems with a commercialization of advanced technologies (in Polish: Zarządzanie technologiami. Zaawansowane technologie i wyzwanie ich komercjalizacji), Difin.

ISO/IEC TR 29110-5-6-2:2014 - Systems and software engineering - Lifecycle Profiles for Very Small Entities (VSEs) - Systems engineering - Management and engineering guide: Generic profile group: Basic profile, International Organization for Standardization/International Electrotechnical Commission: Geneva, Switzerland. Available in English at no cost from ISO at:

http://standards.iso.org/ittf/PubliclyAvailableStandards/c063371_ISO_IEC_29110-5-6_2_20 14.zip and in French at:

http://standards.iso.org/ittf/PubliclyAvailableStandards/index.html

ISO/IEC TR 29110-5-6-1:2015 - Systems and software engineering - Lifecycle Profiles for Very Small Entities (VSEs) - Systems engineering - Management and engineering guide: Generic profile group: Entry profile, International Organization for Standardization/International Electrotechnical Commission: Geneva, Switzerland.

Available at no cost from ISO at:

http://standards.iso.org/ittf/PubliclyAvailableStandards/index.html

Laporte C., Chevalier F. 2015, "An Innovative Approach to the Development of Project Management Processes for Small-scale Projects in a large Engineering Company”, Paper presented at the $2^{\text {th }}$ Annual International Council on Systems Engineering (INCOSE) International Symposium, Seattle, July.

Laporte, C., Hébert, C., Mineau, C., 2014, "Development of a Social Network Website Using the New ISO/IEC 29110 Standard Developed Specifically for Very Small Entities", Software Quality Professional Journal, ASQ, 16(4): 4-25.

Laporte C., Houde R., Marvin J. 2014, "Systems Engineering International Standards and Support Tools for Very Small Enterprises", Paper presents at the $24^{\text {th }}$ Annual International Council on Systems Engineering (INCOSE) International Symposium, Las Vegas, June 30th-July 3, 2014.

Lichtethaler E. 2004, "Technology intelligence processers in leading European and North American multinationals", R\&D Management, 34(2): 121-134.

Mintzberg H. 1994, "The fall and rise of strategic planning", Harvard Business Review, 72(10): 107-114.

Moll R. 2013, "Being prepared: A bird's eye view of SMEs and risk management", ISO Focus+, 4(2): 
16-18.

Phaal R., Farrukh C.J.P., Probert D.R. 2004, “Technology roadmapping - A planning Framework for evolution and resolution", Technological Forecasting and Social Change, 71(1-2): 5-26.

Tidd J., Bessant J. 2009, Managing Innovation: Integrating Technological, Market and Organizational Change (4 $4^{\text {th }}$ Edition), Wiley.

Tidd J., Bodley K. 2002, "The effect of Project novelty on the New product development process", R\&D Management 32(2): 127-138.

Roussel P.A., Saad K.N., Erickson T.J. 1991, Third Generation R\&D: Managing the Link to Corporate Strategy, Boston, Harvard Business School Press.

Walden D.D., Roedler G.J., Forsberg K.J., Hamelin R.D., Shortell (Eds.) 2015, Systems Engineering Handbook: A Guide for System Life Cycle Process and Activities $\left(4^{\text {th }}\right.$ ed.), San Diego CA: International Council on Systems Engineering. Published by John Wiley \& Sons, Inc.

\section{Biography}

Aleksander Buczacki is an assistant professor at Warsaw University of Technology. He specializes in production management and new product development issues based on the Lean Management approach. He is President of the INCOSE Chapter Poland. He has conducted consulting services on Lean Manufacturing and Innovation Management for companies from automotive, machine, aviation, IT industries. He also has provided services for the public sector in development and implementation of Regional Innovation Strategies.

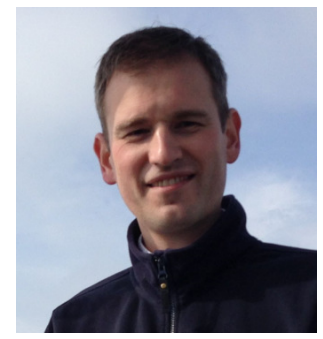

Dr. Claude Y. Laporte has been a professor since 2000 at the École de technologie supérieure (ÉTS), a 9,000-student engineering school, where he teaches software engineering. His research interests include software process improvement in small and very small enterprises, as well as software quality assurance. He has worked in defense and transportation enterprises for over 20 years. He received a Master's degree in Physics from the Université de Montréal, a Master's degree in Applied Sciences from the École Polytechnique de Montréal and a Ph.D. from the Université de Bretagne Occidentale (France). In addition, he was awarded an honorary doctorate by the Universidad de San Martin de Porres (Peru) in 2013. He is the Editor of ISO/IEC JTC1 SC7 Working Group 24, tasked to develop ISO/IEC 29110 life cycle standards and guides for Very Small Entities. He is the Co-chair of the INCOSE Systems Engineering for Very Small Entities WG. He is a member of INCOSE, IEEE, PMI and a member of the professional association of engineers of the Province of Québec (Ordre des ingénieurs du Québec). He is the co-author of two French books on software quality assurance published in 2011 by Hermes Science-Lavoisier and one English textbook, on the same topic, published by John Wiley and Sons in 2016.

Web site address: http://profs.etsmtl.ca/claporte/English/index.html 